九州大学学術情報リポジトリ

Kyushu University Institutional Repository

\title{
A Rapid and Simple Method to Detect Antioxidative Substances on a Thin-Layer Chromatography Plate
}

Nakamura, Takashi

Laboratory of Fisheries Technology, Faculty of Agriculture, Kyushu University

Mukai yama, Tsutomu

Laboratory of Fisheries Technology, Faculty of Agriculture, Kyushu University

Nagayama, Kohki

Laboratory of Fisheries Technology, Faculty of Agriculture, Kyushu University

https://doi.org/10.5109/23973

出版情報: 九州大学大学院農学研究院紀要. 36 (1/2)，pp.93-98，1991-10. Kyushu University バージョン：

権利関係 : 


\title{
A Rapid and Simple Method to Detect Antioxidative Substances on a Thin-Layer Chromatography Plate* 1
}

\author{
Takashi Nakamura*2, T sutomu Mukaiyama and Kohki Nagayama \\ Laboratory of Fisheries Technology, Faculty of Agriculture, \\ Kyushu University, 6-10-1, Hakozaki, Fukuoka 812, Japan
}

(Received July 20, 1991)

\begin{abstract}
A simple, rapid and sensitive method was devised to detect specifically antioxidative substances on a thin-layer chromatography (TLC) plate. After the chromatography on a silica gel plate, the plate was sprayed with a pigment solution and irradiated with ultraviolet light. Only the spots of antioxidative ability were embossed as the background pigment was bleached. Among the pigments tested, paprika pigment (mainly capsanthin), capsanthin, and canthaxanthin were excellent, and p-carotene and astaxanthin were adequate for the spray reagents. Using the paprika spray reagent, antioxidants added to olive oil and tocopherols in a brown alga Ishige okamurae were clearly detected on the TLC plates. Generally, a few minutes of ultraviolet light irradiation with a commercially available illuminator $(2000 \mu \mathrm{W})$ were sufficient, and less than one $\mu \mathrm{g}$ of antioxidative substances on the silica gel plate was detectable.
\end{abstract}

\section{INTRODUCTION}

To facilitate the search for new antioxidants, a simple and rapid method for screening or monitoring of antioxidative substances is needed. Usually, after extraction and chromatographic purification, antioxidative activity of the preparations is evaluated by measuring the retardation of the oxidation of the lipids. The thiobarbituric acid or iodometric method has been used for this purpose (Palmateer et al., 1960 ; Ramarathnam et al., 1989 ; kawashima et al., 1977 ; Aoyama et al., 1982). However, some of these methods are tedious and the latter method requires a relatively large sample size. The weighing method, originally developed by Olcott and Einset (1958), is simple but time consuming ; the test requires days or weeks until an expected weight gain could be obtained (Fujimoto and Kaneda, 1980 ; Ishikawa et al., 1984). Other methods, measuring of bleaching time of carotenoids in oil solution (Bickoff, 1951; Pratt, 1965 ; Marco, 1968), oxygen uptake of the lipid in a Warburg apparatus and the like (Quencer et al., 1964 ; Niki et al., 1984), intensity of chemiluminescence (Niki et al., 1982), or of amounts of specified hydroperoxides by high performance liquid chromatography (Stocker et al., 1987 ; Kohen et al., 1988 ; Terao, 1989), have also been used. All these methods are suitable for a quantitative and comprehensive evaluation of the antioxidant activity of the preparations. However, the methods

\footnotetext{
*1 Presented at the General Meeting of The Japanese Society of Scientific Fisheries, Tokyo, April 1990.

*2 To whom correspondence should be addressed.
} 
described are complicated, tedious and/or time consuming for use in rapid screening or monitoring of unknown antioxidants in preparations containing large amounts of impurities.

Thin-layer chromatography (TLC) is a simple and excellent method for separation of complicated constituents in perparations. However, few detection methods universally specific for antioxidative substances are available. Seino et al. (1971) detected tocopherols and their dimers in the sludge of soybean oil using TLC and a newly-devised method : the TLC plate was sprayed with linoleic acid, then, exposed to ultraviolet (UV) light $(365 \mathrm{~nm})$ for $10 \mathrm{~min}$, and finally sprayed with $1 \% \mathrm{~N}, \mathrm{~N}$-dimethyl$p$-phenylenediamine hydrochloride in ethanol. Pratt (1980) used another spray reagent made up of a-carotene and linoleic acid to detect antioxidative substances on a TLC plate or filter paper. These methods utilizing oxidation of the linoleic acid are simple and resourceful, however, they are time is required to oxidize the unsaturated acids and/or to bleach the carotene ("usually within $3 \mathrm{hr}$ ", described in the text). Furthermore, the resultant yellowish color of the antioxidant spots obtained by the latter method is not sensitive enough to distinguish from colored spots other than the antioxidative substances.

we describe here the development of a more rapid and sensitive method to specifically detect antioxidative substances, using a combination of TLC and subsequent bleaching of sprayed pigments by UV irradiation.

\section{MATERIALS AND METHODS}

Antioxidative substances. 2, 6-Di-tert-butyl- $p$-cresol (BHT), tert-butylhydroquinone (BHQ), 2 [3]-tert-butyl-4-hydroxyanisole (BHA), and ethoxyquin were purchased from Tokyo Kasei Kogyo Co. (Tokyo, Japan). Ascorbic acid, carnosine, capsaicin, glutathione, n-mannitol, DL- $\alpha$-tocopherol and uric acid were obtained from Wako Pure Chemical Ind. (Osaka, Japan). Bilirubin and indomethacin, and hydroquinone were purchased from Sigma Chemical Co. (St. Louis, MO) and Kishida Chemical Co. (Osaka, Japan), respectively.

Pigments. Paprika pigment, commercially available as a food additive, was donated by Takeda Pharmaceutical Ind. (Osaka, Japan). Astaxanthin and canthaxanthin, and shikonin were donated by Dr. Y. Tanaka (Kagoshima University, Japan) and Mitsui Petrochemical Ind. (Tokyo, Japan), respectively. $\beta$-Carotene, purpurin, cochineal pigment, monascus pigment and seven other water soluble pigments were purchased from Wako Pure Chemical Ind. (Osaka, Japan), and capsanthin was obtained from Tokyokasei Kogyo Co. (Tokyo, Japan). Forty-four artificial pigments of food additives were obtained from commercial sources.

Corn oil was purchased from Wako Chemical Ind. (Osaka, Japan). Lipids were extracted from a brown alga Ishige okamurae by the method using $\mathrm{CHCl}_{3} / \mathrm{MeOH}(2$ : $1, \mathrm{v} / \mathrm{v})$ (Folch et al. 1957). All other chemicals were of either first class grade or extra pure grade.

Detection of antioxidative substances. The pigments described were dissolved either in benzene, chloroform, ethanol or in deionezed water $(1-5 \mathrm{mg} / \mathrm{mL})$. After spraying the pigment solution uniformly onto the TLC plate and removing the solvent by air blowing with a hair dryer, the plate was exposed for an appropriate time to UV 
light $(254 \mathrm{~nm})$ with a UV illuminator $(7000 \mu \mathrm{W}$, model 20-TC, Atto Co. Tokyo, Japan). The optimum exposure time was determined by regular interval irradiation. TLC was carried out on a silica gel plate (Silica Gel 60 plate, $250 \mu \mathrm{m}$, E. Merck, Darmstadt, Germany).

\section{RESULTS AND DISCUSSION}

Selection of pigments. After spotting the antioxidants $(2.5,5,10 \mu \mathrm{g} / 2.5 \mu \mathrm{L}$ $\mathrm{CHCl}_{3}$ ) onto silica gel plates, each of the pigment solutions was sprayed, uniformly. The plates were dried with a hair dryer and exposed to UV light, separately and for suitable time. As the background pigment was bleached by UV light, the antioxidant spots were gradually embossed. As shown in Fig. 1, paprika pigment (mainly capsanthin), capsanthin, and canthaxanthin were excellent, and p-carotene and astaxanthin were suitable as spray reagents. Although the p-carotene was able to be sprayed homogeneously, the yellowish color was less clear than the reddish colors of the others. When these carotenoid reagents were used, a few minutes of UV irradiation were sufficient to detect the antioxidant spots. Since the purpurin is more stable than the carotenoids described above, much more time was needed for the background color to fade out on the silica gel plate. The cochineal, monascus and other water soluble pigments were not suitable for detection of the lipoidal antioxidants, though some antioxidant spots were detectable. The shikonin and the artificial pigments (food additives) tested faded little within time of experiment.

Application for TLC. Olive oil $(100 \mu \mathrm{g})$, containing authentic antioxidants ( 0.5 or $2 \mu \mathrm{g}$ ) was separated on a pair of silica gel plates using $\mathrm{n}$-hexane/diethyl ether/acetic acid $(70: 30: 1, \mathrm{v} / \mathrm{v} / \mathrm{v})$ as the developing solvent. One plate was sprayed with a pigment solution and the other was charred with $50 \%$ sulfuric acid. As shown in Fig. 2 (A), using the paprika pigment solution ( $5 \mathrm{mg} / \mathrm{mL} \mathrm{CHCl}_{3}$ ), even $0.5 \mu \mathrm{g}$ of the antioxidants of reddish brown spots was clearly detected without disturbance of olive oil ; the larger amounts of triglycerides were detected only on the plate charred with the sulfuric acid. This method using the paprika pigment solution, usually was more sensitive than that using the sulfuric acid and was also applied to screen or monitor antioxidative substances in algae. As in Fig. 2 (B), three colored bands of antioxidative substances were detected in the extracted lipids of a brown alga Ishige okamurae; they were isolated using this monitoring method and identified to be $\alpha^{-}$, y- and $\delta$-tocopherols. Their total content in the extracted lipids was estimated to be $0.33 \%$ (unpublished data). Authentic antioxidants other than shown in the figures were also tested with the paprika reagent. Colored spots of ascorbic acid, capsaicin, ethoxyquin, hydroquinone and indomethacin were clearly visible. Spots of biological antioxidants, bilirubin (Stocker, 1987) and uric acid (Ames, 1981) were obscure because of their inferior solubility. However, those of other radical scavengers found in biological systems, carnosine (Kohen et al., 1988), glutathione (Tirmenstein and Reed, 1989) and mannitol (Misra and Fridovich, 1976) were not detected as colored spots. Possible reasons for this discrepancy may be due to lack of affinity between the hydrophilic antioxidants and the lipophilic spray reagent, differences of scavenging specificity to the radicals produced or to lower antioxidative activities of the biological antioxidants than that of the carotenoid in the spray reagent ; carotenoids have long been known as antiox- 
idants, scavengers of singlet molecular oxygen in plants (Foote, 1976). Further studies using another pigments are in progress.

Thus, with the combined use of TLC and UV light bleaching of sprayed carotenoids of less than one $\mu \mathrm{g}$ of antioxidative substances led to a clear detection on the TLC plate, with few exceptions. The paprika pigment used in this study is a low priced food additive commercially available in Japan. The UV illuminator is a popular equipment used to detect fluorescent substances on chromatograms or electrophoresis patterns.

\section{ACKNOWLEDGMENTS}

Dr. M. Kitamikado provided advice and encouragement and M. Ohara helpful comments on the manuscript.

\section{REFERENCES}

Ames, B. N., R. Cathcart, E. Schwiers and P. Hochstein 1981 Uric acid provides an antioxidant defense in humans against oxidant- and radical-caused aging and cancer: A hypothesis. Proc. Natl. Acad.Sci. USA $78: 6858-6862$

Aoyama, T., Y. Nakakita, M. Nakagawa and H. Sakai 1982 Screening for antioxidants of microbial origin. Agric. Biol. Chem., $46: 2369-2371$

Bickoff, E. M. 1951 Phenolic antioxidants for carotene. J. Am. Oil Chem. Soc., 28 : 65-68

Folch, J., M. Lees and G. H. Sloane Stanley 1957 A simple method for the isolation and purification of total lipids from animal tissues. J.Biol. Chem. $226: 497-509$

Foote, C. S. 1976 Photosensitized oxidation and singlet oxygen : Consequences in biological systems. In "Free Radicals in Biology", Vol. II, ed. by W. A. Pryor, Academic press, Inc., New York pp. $85^{-133}$

Fujimoto, K. and T. Kaneda 1980 Screening test for antioxygenic compounds from marine algae and fractionation from Eisenia bicyclis and Undaria pinnatifida. Nippon Suisan Gakkaishi, 46 :11251130

Ishikawa, Y., K. Morimoto and T. hamasaki 1984 Flavoglaucin, a metabolite of Eurotium chevalieri, its antioxidation and synergism with tocopherol.J. Am. Oil Chem. Soc., 61 : 1864-1868

Kawashima, K., H. Itoh and I. Chibata 1977 Antioxidant activity of browning products prepared from low molecular carbonyl compounds and amino acids. J. Agric. Food Chem. 25 :202-204

Kohen, R., Y. Yamamoto, K. C. Cundy and B. N. Ames 1988 Antioxidant activity of carnosine, homocarnosine, and anserine present in muscle and brain. Proc. Natl. Acad. Sci. USA, $85: 3175^{-}$ 3179

Marco, G. J. 1968 A rapid method for evaluation of antioxidants. J. Am. Oil Chem. Soc., 45 : 594-598

Misra, H. P. and I. Fridovich 1976 Superoxide dismutase and the oxygen enhancement of radiation lethality. Arch. Biochem. Biophys. $176: 577-581$

Niki, E., R. Tanimura and Y. Kamiya 1982 Oxidation of lipids. II. Rate of inhibition of oxidation by a-tocopherol and hindered phenols measured by chemiluminescence. Bull. Chem Soc. Jpn. 55 : 1551-1555

Niki, E., T. Saito, A. Kawakami and Y. Kamiya 1984 Inhibition of oxidation of methyl linoleate in solution by vitamin E and vitamin C. J.Biol. Chem. $259: 4177-4182$.

Olcott, H. S. and E. Einset 1958 A weighing method for measuring the induction period of marine and other oils. J. Am. Oil Chem. Soc., 35: 161-162

Palmateer, R. E., T. C. Yu and R. 0. Sinnhuber 1960 An accelerated oxidation method for the 
estimation of the storage life of frozen seafoods. Food Technol. 14 : 528-532

Pratt, D. E. 1965 Lipid antioxidants in plant tissue. J. Food Sci., 30 : 737-741

Pratt, D. E. 1980 natural antioxidants of soybeans and other oil-seeds. In "Autoxidation in Food and Biological Systems", ed. by M. G. Simic and M. Karel, Plenum Press, New York. pp. 283-293

Quencer, R. M., P. A. Buck and L. R. Mattick 1964 The kinetics of autoxidation of methyl linoleate. The effect of added antioxidants and a new method for the evaluation of antioxidants. J. Am Oil Chem. Soc., 41: 650-653

Ramarathnam, N., T. Osawa, M. Namiki and S. Kawakishi 1989 Chemical studies on novel rice hull antioxidants. 2. Identification of isovitexin, a C-glycosyl flavonoid. J. Agric. Food Chem., 37 : 316319

Seino, H., S, Watanabe and Y. Abe 1971 Studies on the antioxidative compounds in the deodorizer sludge of soybean oil. J. Jpin. Oil Chem. Soc. 20: 24-29

Stocker, R., Y. Yamamoto, A. F. McDonagh, A. N Glazer and B. N. Ames 1987 Bilirubin is an antioxidant of possible physiological importance. Science $235: 1043-1046$

Terao, J. 1989 Antioxidant activity of p-carotene-related carotenoids in solution. Lipids 24 :659-661

Tirmenstein, M. and D. J. Reed 1989 Effects of glutatione on the a-tocopherol dependent inhibition of nuclear lipid peroxidation. J. Lipid Res. 30: 959-965

\section{LEGENDS}

FIG. 1. Screening of pigments to detect antioxidative substances on a TLC plate. Antioxidants, 2.5, 5 and $10 \mu \mathrm{g}$ in $2.5 \mu \mathrm{L}$ chloroform, were spotted onto a silica gel plate. After spraying the pigment solution and drying with a hair dryer, each plate was exposed to UV light for a suitable time. B HA :2[3]-tert-butyl-4-hydroxyanisole, B HT : 2, 6-di-tert-butyl-p-cresol, B HQ : tert-butylhydroquinone, Toc: a-tocopherol

FIG. 2. Separation and detection of antioxidants by TLC and by the combined use of pigmentspraying and UV light bleaching. (A) : Olive oils $(100 \mu \mathrm{g})$ containing 0.5 and $2 \mu \mathrm{g}$ antioxidants, (B) : Lipids of a brown alga Ishige Okamurae. Both were developed with $\mathbf{n}$-hexane/ethyl ether/ acetic acid (70:30:1, v/v/v) on duplicate silica gel plates (Silicagel 60, $250 \mu \mathrm{m}$ ) respectively. After removing the solvent, one plate was sprayed with $50 \% \quad \mathrm{H}_{2} \mathrm{SO}_{4}$ and charred, while the other was sprayed with a paprika pigment solution $\left(5 \mathrm{mg} / \mathrm{mLCHCl}_{3}\right)$ and exposed to UV light. Abbreviations used in the figures are the same as in FIG. 1. TG : triglycerides 


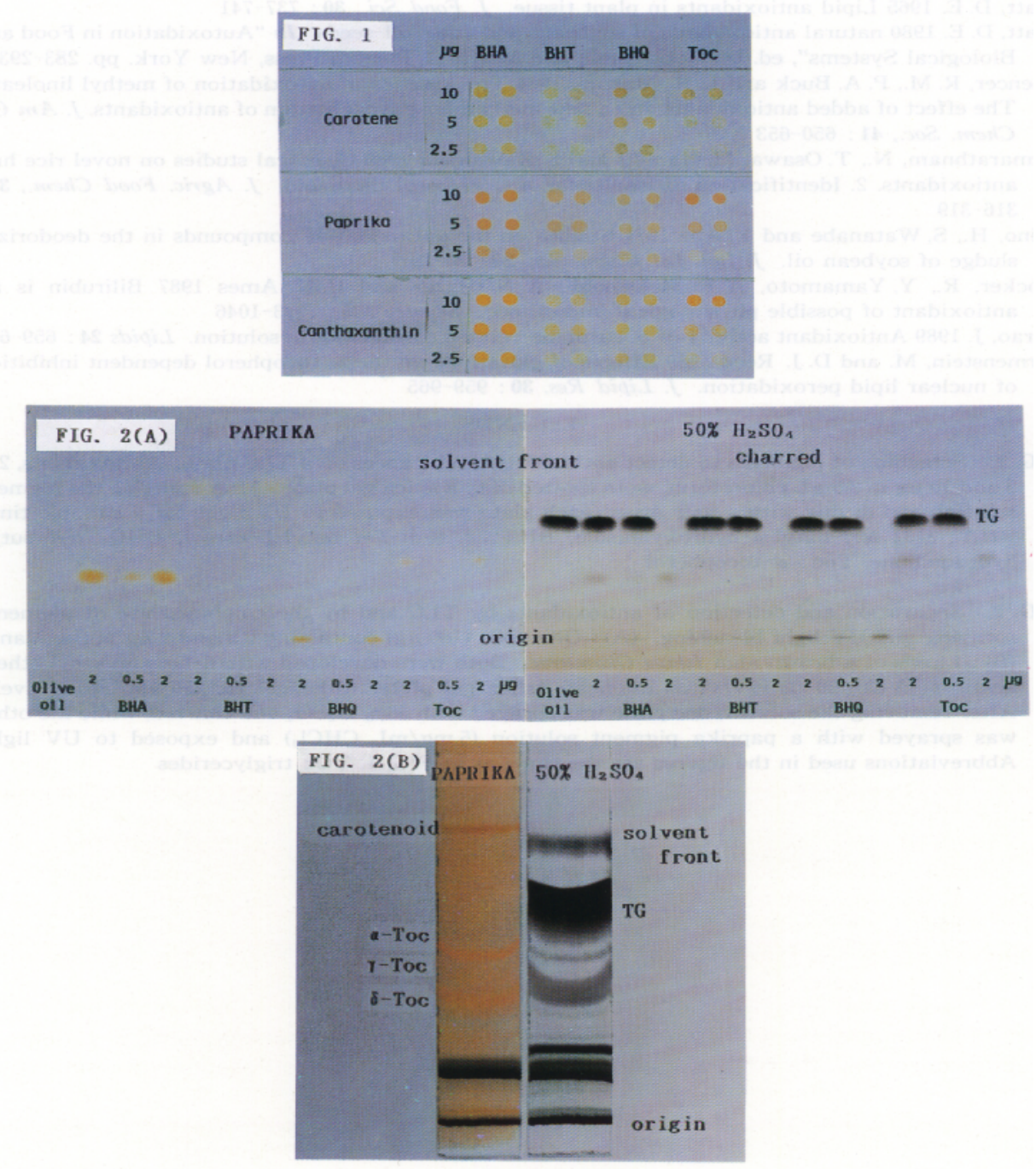

